\title{
Editorial
}

\section{The nature of music itself, and the knowledge versus skills debate in music education}

Back in 2013, in the BJME editorial for issue 30(2), we considered the place of knowledge in the curriculum (Fautley \& Murphy, 2013). Things have not stood still since that date, certainly in England, and other parts of the world too. What we have now is a situation where the idea of knowledge as assuming supremacy over skills is on the increase. For those of us concerned with music education, many aspects of this increasingly fractious debate are to be viewed with concern. Allied to this, we have neoliberal-leaning governments in many parts of the world, Britain included, who seem to find it difficult to understand the important role that music education has - or should have - in the education of our children and young people. Indeed, in the UK, the education secretary is on record as making this observation:

Education secretary Nicky Morgan has warned young people that choosing to study arts subjects at school could 'hold them back for the rest of their lives' (The Stage, 2014)

This attitude, and Britain is certainly not alone in this, is clearly going to be problematic for those of us involved in music and the arts.

The vary nature of music itself makes it sometimes hard to justify its place in the school curriculum to politicians, administrators, newspapers, and the general public. In another editorial (Fautley \& Murphy, 2015) we have deliberated on the nature of music education. But it is not only music education which can occupy a problematic location; the parent domain of music itself is also difficult to define and quantify, as lan Cross observes:

\footnotetext{
For those engaged in understanding music as it manifests itself across different cultures and historical times, 'music' appears to be protean, and its identification in any consistent manner seems particularly intractable. Certainly, music cannot be defined in the terms in which it is conventionally conceived of in contemporary Western societies, as a consumable commodity constituted of complexly patterned sound that is produced by a class of specialists and engaged with through listening for primarily hedonic reasons. In many, perhaps most, non-Western cultures it involves overt action and active group engagement... (Cross, 2009, p. 6)
}

But when questions are asked at the highest governmental and societal levels as to the place and value of the subject matter of this journal, then clearly we do need to be concerned, and we need to think about how to respond. But what has this got to do with skills and knowledge? Well, one of the common arguments employed by those proposing such things as a 'knowledge-rich curriculum' is that knowledge trumps skills every time. Admittedly, such people are seldom from a music education background, but even so we need to have 
thought about what an appropriate response might be. For example, a statement that all music educators are likely to agree with is that no matter how much factual information a learner knows (if this is what a knowledge curriculum means to those touting it), they are unlikely to be able to do anything very meaningful with it when it comes to playing any sort of musical instrument, no matter how simple or complex. As Pascual-Leone observes, with regards to himself:

Playing a musical instrument requires more than factual knowledge about the musical instrument and the mechanics of how it is played. For example, given complete information about hand position, finger motions, and sequence of keys to push for how long and with what force, I would still be unable to play even the simplest piano sonata. (Pascual-Leone, 2001, p.315)

And we would agree with that from the perspectives of the learners we have taught! It seems most unlikely that any sensible music educator would ever only teach about playing the keyboard, without ever letting the child or young person actually have a go on one, would they? We do not have trumpet lessons about the trumpet, where only essay-writing skills are demonstrated. A beginner trumpet learner wants a hands-on experience, else they will soon get bored and give up.

Interestingly, one of the things we do know about musical skills is that they seem to be universal, and start from a very early age:

[A] surprising thing about music is that all humans, including infants, possess basic musical skills. (Parncutt, 2009, p.223)

and in music education we know we have colleagues working with neonates, as well as with children, young people, and adults of all ages and stages. What this all means when put together is that maybe it is the case that in music education we really understand what skills are, and that we are in danger of having our deep and nuanced understandings swamped by those from other domains who lack our perceptions and insights. This would not be the first time such a thing has happened in and to music education.

But returning to skills, faced with comments such as those from the British secretary of state cited above, a music teacher can be in a difficult situation with regards to influencing parents. After all, for the parents of a child showing early signs of musical promise, the word of a lone music teacher placed against those of a government minister will be weighed accordingly, and with sentiments such as those espoused in the cited example above, this could be a difficult discussion to have. But it will be an important one, as we know that parental involvement in the development of early music skills is significant:

There is considerable evidence that parents have a vital influence on children's motivation for involvement with music and the acquisition of musical skill ... Another important contributor to motivated students is the relationship between teachers, parents and learners... (Hallam, 2009, p.290) 
So the role of the music teacher in countering the problematic statements of politicians can sometimes feel like a lone path. It is here that journals such as the BJME can be of significant help, delivering a solid research base, arising from careful scholarship, that clearly demonstrate the importance of our subject, and which can be used to help inform thinking and discourse. After all, much political thought, in the UK at least, is concerned with the implementation of ideologically-based rather than evidence-informed policy. We need to work away at countering any such ill-informed political arguments, as well as providing material which is both informative and thought-provoking too.

Which takes us nicely to the articles which we are presenting in this edition of the BJME. As usual, we have a selection of articles from around the world, which look at our themes of both knowledge and skills from a variety of international perspectives. To begin with, Hallam, Creech, and McQueen, writing from England, describe the impact of a musical futures approach, based on informal learning methodologies, where children and young people determine their own learning targets. They find that senior management in the school do see benefits from the adoption of this way of working.

From Washington state in the USA, Roberts takes us into the world of singing games in the Primary school. He finds that competition, and a competitive element, are popular amongst the children concerned. Interestingly, though, it is not the competitive element per se that the children enjoy, but the level of activity and action involved with it. Moving then to Sweden, Wallerstedt and Lindgren take us in to the secondary school, but also to the out-of-school lives of these students. The place of the formal and informal in music education is of international importance, and here the authors ask us to consider difficult questions, not only of what should be taught and learned, but also the styles, types and genres which are appropriate for this.

Writing from an Australian perspective, Davidson and Lupton look at taking a new slant on the pedagogy of music theory. They argue that new times call for new ideas, and, having some aspects in common with both the Hallam et al and the Wallerstedt and Lindgren pieces in this issue, that to be truly inclusive, such courses need to take account of a variety of musical styles, types, and genres. Remaining in Australia for our next article, Harrison and Grant describe the variety of career trajectories open to higher research degree students. They look at the perceptions of these students, and make recommendations with regards to what could be done by both institutions and supervisors to help provide opportunities with the next stages of these newly emerging higher degree graduates with their future careers.

Finally, writing from an English perspective, but taking us into the sound-world of the Javanese Gamelan, Haddon discusses the ways in which learning the Gamelan causes Western students to rethink many of their preconceptions regarding musical learning. She finds that far from being a distraction, such students can seriously benefit from exposure to this different way of working.

The articles in this edition of the $B J M E$, then, attest to the wide variety of approaches which educators in many parts of the world are invoking to address the complex issues of music education today. We hope they are noticed!

MARTIN FAUTLEY and REGINA MURPHY

BJME Co-Editors 


\section{References}

CROSS, I. (2009) The nature of music and its evolution. In I. Cross, S. Hallam \& M. Thaut (Eds.), The Oxford Handbook of Music Psychology, pp. 3-13. Oxford: Oxford University Press.

FAUTLEY, M. \& MURPHY, R. (2013) Editorial. British Journal of Music Education, 30(2), 157-9.

FAUTLEY, M. \& MURPHY, R. (2015) What is music education? - Editorial. British Journal of Music Education, $32(1), 1-4$.

HALLAM, S. (2009) Motivation to learn. In I. Cross, S. Hallam \& M. Thaut (Eds.), The Oxford Handbook of Music Psychology, pp. 285-94. Oxford: Oxford University Press.

PARNCUTT, R. (2009) Prenatal development and the phylogeny and ontogeny of music. In I. Cross, S. Hallam \& M. Thaut (Eds.), The Oxford Handbook of Music Psychology, pp. 219-28. Oxford, Oxford University Press.

PASCUAL-LEONE, A. (2001) The brain that plays music and is changed by it. Annals of the New York Academy of Sciences, 930(1), 315-29.

STAGE, THE. Newspaper (2014). Available online at https://www.thestage.co.uk/news/2014/educationsecretary-nicky-morgan-arts-subjects-limit-career-choices/ [accessed May 2016] 